\title{
PENGARUH PENDIDIKAN KESEHATAN DENGAN VIDEO EDUKASI TENTAG BULLYING TEHADAP PERILAKU BULLYING PADA ANAK DI SD PUJOKUSUMAN 1 YOGYAKARTA
}

Firna Yolanda ${ }^{1}$, Gani Apriningtyas Budiyati ${ }^{2}$

STIKES Surya Global

Yogyakarta, 085229504162

E-mail : virnalahat@gmail.com

\begin{abstract}
ABSTRAK
Latar Belakang: Perilaku bullying adalah tindakan atau perilaku dimana terjadinya penyalahgunaan kekuatan yang dilakukan anak baik secara fisik maupun secara verbal. Perilaku bullying memiliki dampak yang negatif bagi anak apabila tidak segera ditangani. Sekolah merupakan rumah kedua untuk anak usia sekolah yang membutuhkan informasi tentang perilaku bullying, maka dari itu pengguanaan video merupakan media yang paling sesuai dengan anak usia sekolah dalam memberikan pendidikan kesehatan. Tujuan : Untuk mengetahui pengaruh pendidikan kesehatan dengan video edukasi tentang bullying terhadap perilaku bullying pada anak di SD Negeri Pujokusuman 1 Yogyakarta. Metode : Jenis penelitian ini menggunakan desain penelitian Experimen dengan one-group pra-post test design. Teknik pengambilan sampel menggunakan total sampling dengan jumlah sampel 60 siswa di SD Negeri Pujokusuman 1 Yogyakarta. Teknik analisa data menggunakan Wilcoxon Signed Rank Test, Instrumen penelitian menggunakan lembar kuesioner perilaku bullying dan video edukasi tentang bullying. Hasil : Hasil penelitian menunjukkan bahwa sebelum diberikan pendidikan kesehatan tentang perilaku bullying pada anak mayoritas dalam kategori sedang yaitu sebanyak 49 responden (81\%) dan setelah diberikan pendidikan kesehatan tentang perilaku bullying pada anak mayoritas dalam kategori rendah yaitu sebanyak 52 responden (86,7\%). Kesimpulan : Terdapat pengaruh sebelum dan sesudah pemberian pendidikan kesehatan dengan video edukasi tentang bullying terhadap perilaku bullying pada anak di SD Negeri Pujokusuman 1 Yogyakarta dengan nilai $p$ value $=0,000(<$ $0,05)$.
\end{abstract}

Kata kunci : Bullying, Pendidikan kesehatan, Video edukasi.

\begin{abstract}
Background:Bullying behavior is the actions or behaviors in which the abuse of force is carried out by the child both physically and verbally. Bullying behavior have the negative impact to the children if not treat immediately. The school is a second home for school aged children which have the information about billying behavior. With the using viseo is the true media to the student in give the health education. Objective: to find out the effect of health education with educational videos about bullying on bullying behavior in children in elementary school Pujokusuman 1 Yogyakarta. Method: This type of research uses a Experiment research design with one group pre-post test design. The sampling technique used total sampling with a total of 60 students in elementary school Pujokusuman 1 Yogyakarta. The data analysis technique used a Wilcoxon Signed Rank Test. The research instruments used the kuesioner sheet of bullying behavior and educational videos about bullying. Results: The results showed that before being given health education about bullying behavior in the majority of children in the medium category as an many as 49 respondents (81\%) and after being given health education about bullying behavior in the majority of children werw in the low category as many as 52 respondents (86,7\%). Conclusion:there is have an effect before and after of providing
\end{abstract}


health educational with educational videos about bullying on bullying behavior in elementary school Pujokusuman 1 Yogyakarta with the $p$ value $=0,000(<0,05)$

Keywords: Bullying, Health Education, Educational Video

\section{Latar Belakang}

Salah satu fenomena yang menyita perhatian di dunia pendidikan pada saat ini adalah kekerasan di sekolah, baik yang dilakukan guru terhadap siswa, maupun oleh siswa terhadap siswa lainnya. Bullying adalah bentuk-bentuk kekerasan dimana terjadi pemaksaan secara psikologis ataupun fisik terhadap seseorang ataupun kelompok orang yang lebih lemah oleh seseorang yang lebih kuat atau seseorang yang memiliki power (kekuasaan) untuk melakukan apa saja terhadap korbannya. Korban juga mempresepsikan dirinya sebagai pihak yang lemah, tidak berdaya selalu terancam oleh bully (Putri, 2018).

Komisi Perlindungan Anak pada tahun 2017 menyatakan bahwa anak-anak di 18 propinsi di Indonesia memperlihatkan bahwa sekolah dapat menjadi tempat yang cukup berbahaya bagi anak-anak, jika kekerasan tidak diantisipasi. Kasus kekerasan terhadap anakanak sekolah menduduki peringkat kedua setelah kekerasan anak-anak dalam keluarga. Jika siswa sering menjadi korban kekerasan, mereka dapat memiliki watak keras di masa depan. Kekerasan/bullying ini telah lama menjadi bagian dari dinamika sekolah. Istilah bullying sendiri memiliki makna yang mencakup berbagai bentuk penggunaan kekuasaan atau kekuatan untuk menyakiti orang lain sehingga korban merasa tertekan, trauma dan tak berdaya (Wiyani, 2014).
Di Indonesia KPAI mencatat jumlah kasus kekerasan terhadap anak di bidang pendidikan per 30 Mei 2018 sebanyak 161 kasus. Korban tawuran sebanyak 23 kasus (14,3\%), anak pelaku tawuran sebanyak 31 kasus (19,3\%), dan kasus anak korban bullying sebanyak 36 kasus $(22,4 \%)$. Selanjutnya, kasus anak pelaku bullying sebanyak 41 kasus $(25,5 \%)$ dan kasus anak korban kebijakan pendidikan sebanyak 30 kasus $(18,7 \%)$. Kasus terbanyak berasal dari jenjang SD sebanyak 13 kasus (48\%), disusul dari jenjang SMA/SMK berjumlah sembilan kasus $(34,7 \%)$ dan SMP sebanyak lima kasus $(17,3 \%)$. KPAI mengungkapkan, Yogyakarta menduduki 5 besar kasus dengan pengaduan kekerasan (Pratama, 2018). Kota Yogyakarta menduduki peringkat tertinggi dalam kasus bullying atau kekerasan di sekolah. Banyaknya jumlah sekolah di kota Yogyakarta yang merupakan kota pelajar, memungkinkan banyaknya kejadian kekerasan di sekolah dibanding kota lain (Danu, 2013).

Salah satu upaya menambah pengetahuan siswa tentang perilaku bullying yaitu dengan cara memberikan pendidikan kesehatan. Pendidikan kesehatan adalah suatu Upaya untuk mempengaruhi masyarakat, baik individu, maupun kelompok agar mereka berperilaku hidup sehat. Dari batasan ini dapat dilihat bahwa target pendidikan kesehatan hanya perilaku, utamanya perubahan perilaku (behavior chaning) (Notoatmodjo dkk, 2012). Pendidikan kesehatan sangat penting diberikan oleh perawat untuk mengubah perilaku 
individu, keluarga, dan masyarakat sehingga mencapai perilaku hidup sehat. Pendidikan kesehatan yang dilakukan oleh perawat bertujuan untuk mengubah perilaku individu, keluarga dan masyarakat sehinga memiliki perilaku yang sehat dan berperan aktif mempertahankan kesehatan.

Perubahan perilaku tidak hanya sekedar diberikan pengetahuan, pemahaman dan informasi-informasi tentang kesehatan. Untuk terjadi perubahan perilaku diperlukan faktor lain yang berupa fasilitas atau sarana dan prasana untuk mendukung terjadinya perilaku (Notoatmodjo dkk, 2012). Media promosi kesehatan merupakan salah satu sarana atau upaya yang dapat digunakan untuk menampilkan pesan atau informasi kesehatan yang ingin disampaikan sehingga meningkatkan pengetahuan yang akhirnya diharapkan dapat merubah perilakunya kearah positif atau mendukung terhadap kesehatan (Aeni \& Yuhandini, 2018).

Dalam penelitian ini, peneliti menggunakan media video karena penggunaan video dapat menarik pehatian anak-anak, hal ini sejalan dengan penelitian yang dilakukan oleh Aeni \& Yuhandini (2018), didapatkan hasil setelah diberikan intervensi video siswa mengalami kenaikan pengetahuan yang sangat tinggi.

Berdasarkan hasil wawancara yang dilakukan peneliti kepada guru di sekolah, mereka mengatakan bahwa perilaku kekerasan (bullying) masih sering terjadi di sekolah bahkan hampir setiap hari. Perilaku bullying yang sering kali dilakukan oleh siswa yaitu memanggil nama temannya dengan nama orang tua, mengejek, menendang dan memukul. Peneliti juga melakukan wawancara pada 15 orang siswa, mereka semua mengatakan pernah mengalami bullying, mereka mengaku sering diejek, ditendang dan sering dipanggil dengan nama orang tua. Saat peneliti menanyakan apakah dari ke 15 siswa itu pernah melakukan tindakan bullying, ternyata ada 4 orang siswa yang mengatakan pernah melakukan tindakan bullying mereka mengaku bahwa mereka membully karena ikut-ikutan temannya.

\section{Metode}

Metode penelitian yang digunakan dalam penelitian ini adalah metode kuantitatif dengan desain penelitian experimen dan rancangan One group pra-post test design. Tempat penelitian dan waktu penelitian dilakukan di SdNegeri Pujokusuman 1 Yogyakarta pada bulan Juli 2019. Populasi dalam penelitian ini adalah seluruh siswa kelas 5 SD yang sudah mendapatkan persetujuan dari orang tua untuk menjadi responden dengan jumlah 60 siswa. Sampel dalam penelitian ini berjumlah 60 yang diambil dengan teknik total Sampling.

\section{Hasil}

\section{Analisa Univariat}

\section{1) Karakteristik Responden}

Tabel 1

Distribusi Frekuensi KarakteristikResponen Di SD Negeri Pujokusuman 1 Yogyakarta (n

\begin{tabular}{lcc} 
& $=60)$ & \\
\hline $\begin{array}{l}\text { Karakteristik } \\
\text { responden }\end{array}$ & $\mathbf{F}(\mathbf{n})$ & $\mathbf{P}(\%)$ \\
\hline $\begin{array}{l}\text { Umur } \\
11 \text { tahun }\end{array}$ & 18 & 30,0 \\
12 tahun & 42 & 70,0 \\
\hline Jenis kelamin & & \\
Laki-laki & 37 & 61,7 \\
Perempuan & 23 & 38,3 \\
\hline Total & 60 & 100,0 \\
\hline Sumber: Data Primer $(2019)$ &
\end{tabular}

Sumber: Data Primer (2019) 
Hasil analisis pada tabel 1 dapat dilihat bahwa kelompok umur responden yang berada di SD Negeri Pujokusuman 1

Yogyakarta, responden berumur 12 tahun (70,0\%). Sedangkan untuk karakteristik jenis kelamin, mayoritas responden berjenis kelamin laki-laki yaitu 37 (61,7\%).

\section{2) Distribusi frekuensi perilaku bullying} sebelum diberikan pendidikan kesehatan

Tabel 2

Distribusi Frekuensi Perilaku Bullying

Sebelum Pendidikan Kesehatan $(\mathrm{n}=60)$

\begin{tabular}{ccc}
\hline Kategori & F (n) & $\mathbf{P}(\boldsymbol{\%})$ \\
\hline Tinggi & 0 & 0,0 \\
Sedang & 49 & 81,7 \\
Rendah & 11 & 18,3 \\
\hline Total & 60 & 100,0
\end{tabular}

Sumber : Data Primer (2019).

Tabel 2 menunjukkan bahwa perilaku bullying sebelum dilakukan pendidikan kesehatan didapatkan responden paling banyak berada dalam kategori sedang yaitu sebanyak 49 responden $(81,7 \%)$ dan yang paling sedikit berada pada kategori rendah yaitu sebanyak 11 responden $(18,3 \%)$.

3) Distribusi frekuensi perilaku bullying setelah diberikan pendidikan kesehatan

Tabel 3

Distribusi frekuensi perilaku bullying setelah pendidikan kesehatan $(\mathrm{n}=60)$

\begin{tabular}{ccc}
\hline Kategori & F (n) & $\begin{array}{c}\text { Persentase } \\
(\mathbf{\%})\end{array}$ \\
\hline Tinggi & 0 & 0,0 \\
Sedang & 8 & 13,3 \\
Rendah & 52 & 86,7 \\
\hline Total & 60 & 100,0 \\
\hline
\end{tabular}

Sumber : Data Primer (2019).

Tabel 3 menunjukkan bahwa perilaku bullying setelah dilakukan pendidikan kesehatan didapatkan responden paling banyak berada di kategori rendah yaitu sebanyak 52 responden $(86,7 \%)$ dan yang paling sedikit berada pada kategori sedang yaitu sebanyak 8 responden $(13,3$
$\%)$.

\section{Analisa Bivariat}

1) Penelitian ini menggunakan uji normalitas Kolmogorov-Smirnov

Tabel 4

\begin{tabular}{lcc}
\hline \multicolumn{1}{c}{ Variabel } & Pretest & Posttest \\
\hline $\begin{array}{l}\text { Mean } \\
\text { Standar } \\
\text { deviation }\end{array}$ & 2,18 & 2,87 \\
$\begin{array}{l}\text { Kolmogorov } \\
\text { Smirnov Z }\end{array}$ & 39085 & .343 \\
\hline $\begin{array}{l}\text { Asymp.Sig } \\
\text { (2-tailed) }\end{array}$ & 0,000 & 0,000 \\
\hline
\end{tabular}

Sumber : Data Primer, (2019)

Berdasarkan uji normalitas diatas, nilai signifikasi pre test sebesar $0,000<0,05$, sehingga dapat disimpulkan sebaran data untuk pre test berdistribusi tidak normal. Sedangkan nilai signifikasi post test sebesar 0,000 $<0,05$, sehingga dapat disimpulkan sebaran data untuk post test berdistribusi tidak normal. Berdasarkan hasil nilai signifikasi tersebut dapat dilanjutkan uji Wilcoxon Signed Rank Test.

\section{2) Uji Wilcoxon Signed Rank Test}

Hasil Uji Wilcoxon Pengaruh Pendidikan Kesehatan Dengan Video Edukasi Tentang Bullying Terhadap Perilaku Bullying Pada Anak Di SD Negeri Pujokusuman 1 Yogyakarta.

Tabel 5

Hasil Uji Wilcoxon Pengaruh Pendidikan Kesehatan Dengan Video Edukasi Tentang Bullying Terhadap Perilaku Bullying Pada Anak Di SD Negeri Pujokusuman 1 Yogyakarta

\begin{tabular}{lllll}
\hline Variabel & Nilai z & $\begin{array}{l}\text { Asymp. } \\
\text { sig }\end{array}$ & Ket \\
\hline Pree test & -6.403 & 0,000 & Ada \\
$-\quad$ post & & & pengaruh \\
test & & & & \\
\hline
\end{tabular}

Sumber : Data primer,(2019)

Dari tabel 5 dapat kita ketahui nilai Z hitung sebesar $-6,403$ dengan nilai signifikan sebesar 0,000 , hal ini menunjukan bahwa nilai $\mathrm{Z}$ hitung $>\mathrm{Z}$ 
tabel dan Ha diterima, hal ini menunjukkan bahwa perbedaan perilaku bullying sebelum dan sesudah diberikan pendidikan kesehatan dengan video edukasi tentang bullying.

\section{Pembahasan}

\section{Karakteristik responden}

Hasil analisis pada tabel 4.2 menyatakan bahwa kelompok umur responden yang berada di SD Negeri Pujokusuman 1 Yogyakarta, mayoritas berumur 12 tahun (70,0\%). Sedangkan untuk karakteristik jenis kelamin, mayoritas responden berjenis kelamin laki-laki yaitu 37 (61,7\%).

Responden dalam penelitian ini adalah anak sekolah dasar (SD), dimana anak-anak pada jenjang sekolah dasar masih dalam proses pertumbuhan dan pembentukan karakter. Berdasarkan hasil penelitian yang dilakukan oleh peneliti menunjukan bahwa anak-anak jenjang sekolah dasar lebih banyak melakukan perilaku bullying baik yang mereka sadari maupun yang tidak mereka sadari baik itu bullying fisik maupun bullying verbal. Hal ini sejalan dengan penelitian yang dilakukan oleh Sari (2015), menunjukkan hasil bahwa anak dalam jenjang pendidikan SD memang lebih sering melakukan bullying dalam bentuk ucapan (verbal), sedangkan bullying psikologis tidak sering terjadi seperti bullying fisik ataupun bullying non verbal.

Salah satu faktor yang mempengaruhi bullying adalah usia anak sekolah (6-12 tahun), dimana pada periode ini anak mulai diarahkan keluar dari kelompok keluarga dan mulai berinteraksi dengan lingkungan sosial yang akan berdampak pada hubungan interaksi dengan teman sebaya (Rohman, 2016). Hal ini sejalan dengan teori yang dijelaskan oleh Potter \& Perry (2005) dalam Diyanti, Yani \& Lismawati (2015), juga menyatakan bahwa usia sekolah (6-12 tahun) adalah masa dimana terjadi pertumbuhan yang beragam pada pertumbuhan dan perkembangan anak yang akan mempengaruhi pembentukan karakteristik dan kepribadian anak.

Pada penelitian ini diketahui bahwa mayoritas $37(61,7 \%)$ responden berjenis kelamin laki-laki. Adapun $23 \quad(38,3 \%)$ responden lainnya diketahui berjenis kelamin perempuan. Berdasarkan hasil penelitian yang dilakukan oleh peneliti bahwa anak laki-laki cenderung paling banyak melakukan bullying seperti mendorong teman dan mengejek teman, namun bukan berarti perempuan tidak melakukkan perilaku bullying. Hal ini sejalan dengan penelitian yang dilakukan oleh Damantari dalam Murachela (2017), yang menyatakan bahwa perilaku bullying lebih menonjol terjadi pada kalangan lakilaki daripada perempuan, selain itu dikatakan pula bahwa jenis kelamin turut menjadi salah satu faktor perilaku bullying, bahwa laki-laki cendrung setuju dengan perilaku bullying namun bukan berarti bahwa perempuan tidak setuju dengan bullying. 
Hasil penelitian yang dilakukan oleh Aulya, Ilyas \& Ifdil (2016), menyatakan bahwa perilaku agresif siswa laki-laki pada umumnya berada pada kategori sedang (38\%), sedangkan perilaku agresif siswa perempuan pada umumnya berada pada kategori rendah $(36 \%)$.

2. Perilaku bullying pada anak di SD Negeri Pujokusuman 1 Yogyakarta sebelum diberikan pendidikan kesehatan.

Penelitian tentang pengaruh pendidikan dengan video edukasi tentang bullying terhadap perilaku bullying pada anak di SD Negeri Pujokusuman 1 Yogyakarta dengan jumlah responden 60 orang. Berdasarkan hasil penelitian sebelum diberikan pendidikan kesehatan kepada responden dapat dilihat pada tabel 4.3 bahwa responden berperilaku bullying sebagian besar dalam kategori sedang yaitu 49 responden $(81,7 \%)$, sedangkan dalam kategori rendah yaitu 11 responden (18,3\%). Hal ini sejalan dengan penelitian yang dilakukan oleh Araya, Natalia \& Marida (2018), yang menunjukkan bahwa perilaku sebelum diberikan pendidikan kesehatan masih banyak responden yang memiliki nilai sikap cukup dengan hasil responden sikap baik berjumlah 21 (35\%) dan sikap cukup berjumlah 39 responden $(65 \%)$.

Hasil penelitian Saputri, Hartati \& Galuh (2018), juga menunjukkan bahwa terdapat perbedaan perilaku sebelum dan sesudah pendidikan kesehatan dimana nilai median pada perilaku sebelum diberikan pendidikan kesehatan sebesar 21 dengan nilai minimum 14 dan nilai maksimum 25, kemudian nilai median pada perilaku setelah diberikan pendidikan kesehatan sebesar 24 dengan nilai minimum 19 dan nilai maksimum 25 dengan artian terdapat perbedaan peningkatan perilaku sebelum dan sesudah diberikan pendidikan kesehatan. Hal ini sejalan dengan penelitian yang dilakukan oleh Suryaningseh (2016), yang menunjukkan bahwa respoden pada kelompok eksperimen dan kelompok kontrol sebelum dilakukkan pendidikan kesehatan sama-sama berada pada kategori sedang diamana pada kelompok eksperimen, yaitu sebanyak 34 responden (97\%) dan pada kelompok kontrol sebanyak 27 responden $(81,8)$.

3. Perilaku bullying pada anak di SD Negeri Pujokusuman 1 Yogyakarta setelah dilakukan pendidikan kesehatan.

Penelitian tentang pengaruh pendidikan dengan video edukasi tentang bullying terhadap perilaku bullying pada anak di SD Negeri Pujokusuman 1 Yogyakarta dengan jumlah responden 60 orang.

Berdasarkan hasil penelitian sesudah diberikan pendidikan kesehatan kepada 41 responden dapat dilihat pada tabel 4.4 bahwa perilaku bullying pada responden sebagian besar dalam kategori rendah 52 responden $(86,7 \%)$, sedangkan dalam kategori sedang yaitu 8 responden $(13,3 \%)$. Hal tersebut disebabkan karena 
pemberian materi pendidikan kesehatan terkait perilaku bullying tentang dampak dari bullying baik bagi korban, pelaku dan saksi bullying, serta pemberian materi mengenai bagaimana cara menghadapi bullying, sehingga setelah diberikan pendidikan kesehatan responden mengalami peurunan perilaku bullying ketika dilakukan post test.

Menurut Notoatmodjo (2012), menyatakan bahwa pendidikan kesehatan merupakan suatu bentuk intervensi atau upaya yang ditujukan kepada perilaku, agar perilaku tersebut menjadi kondusif untuk kesehatan, dengan kata lain pendidikan kesehatan merupakan upaya agar perilaku individu, kelompok atau masyarakat mempunyai pengaruh positif terhadap pemeliharaan dan peningkatan kesehatan. Hal ini sejalan dengan penelitian yang dilakukkan oleh PH, Yulianto, \& Hermanto (2018), tentang pengaruh pendidikan kesehatan personal hygiene terhadap tingkat pengetahuan dan sikap masyarakat, menyatakan bahwa adanya peningkatan sikap sebelum dan sesudah dilakukan pendidikan kesehatan, hasil penelitian menunjukkan responden mempunyai sikap yang lebih baik dari sebelum pendidikan kesehatan dengan hasil $p$ value $=0,038(<0,05)$.

Menurut Nursaid, Hartini \& Astuti (2016), tentang pengaruh pendidikan kesehatan bahaya merokok terhadap preubahan sikap anak tentang merokok di SDIT Al-Firdaus Gubug, menyatakan bahwa adanya perbedaan sikap sebelum dan sesudah pendidikan kesehatan.

\section{Pengaruh pendidikan kesehatan} dengan video edukasi tentang bullying terhadap perilaku bullying pada anak di SD Negeri Pujokusuman 1 Yogyakarta

Penelitian pengaruh pendidikan kesehatan dengan video edukasi tentang bullying terhadap perilaku bullying pada anak di SD Negeri Pujokusuman 1 Yogyakarta. Hasil analisa menggunakan uji Wilcoxon Signed Rank Test menunjukkan adanya pengaruh pendidikan kesehatan dengan video edukasi tentang bullying terhadap perilaku bullying pada anak di SD Negeri Pujokusuman 1 Yogyakarta dan terdapat perbedaan yang signifikan antara sebelum dan sesudah diberikan pendidikan kesehatan. Hal ini dikarenakan nilai $p=0,000<a=0,05$ dengan artian Ha diterima. Hasil distribusi frekuensi sebelum dan sesudah pendidikan kesehatan juga menunjukkan adanya perubahan perilaku. Pemberian pendidikan kesehatan dengan video edukasi tentang bullying terhadap perilaku bulying pada anak akan meningkatkan pengetahuan pada anak dalam menjaga perilaku nya dalam bersikap.

Dalam pemberian pendidikan kesehatan terdapat beberapa metode yang dapat digunakan. Berdasarkan hasil penelitian yang dilakukan oleh peneliti, 
penggunaan media video lebih efektif digunakan dalam pemberian pendidikan kesehatan, karena dengan menggunakan video ini anak-anak lebih memperhatikan dan lebih mengerti maksud dari materi yang disampaikan. Hal ini sejalan dengan teori yang di sampaikan oleh Notoatmodjo, (2012) yang menyatakan bahwa kegiatan pendidikan kesehatan untuk mencapai tujuan yakni perubahan perilaku, dipengaruhi oleh beberapa faktor seperti faktor metode dan alat-alat bantu/peraga atau media yang dipakai.

Hal ini sejalan dengan penelitian yang dilakukan oleh Rahmawati (2017), yang menyatakan bahwa setelah diberikan pendidikan kesehatan dengan media audiovisual responden mengalami peningkatan, yang menunjukkan bahwa responden menyerap informasi yang diberikan melalui pendidikan kesehatan melalui media audiovisual

\section{Kesimpulan}

Berdasarkan hasil analisa data dan pembahasan yang telah dikemukakan pada bab IV, dapat diambil kesimpulan sebagai berikut:

1. Perilaku bullying pada anak di SD Negeri Pujokusuman 1 Yogyakarta sebelum dilakukan pendidikan kesehatan dengan video edukasi tentang bullying menunjukkan bahwa responden paling banyak yang berada dalam kategori sedang yaitu sebanyak 49 responden $(81,7 \%)$ dan yang paling sedikit berada pada kategori rendah yaitu sebanyak 11 responden $(18,3 \%)$.

2. Perilaku bullying pada anak di SD Negeri Pujokusuman 1 Yogyakarta setelah dilakukan pendidikan kesehatan dengan video edukasi tentang bullying menunjukkan bahwa responden paling banyak berada di kategori rendah yaitu sebanyak 52 responden $(86,7 \%)$ dan yang paling sedikit berada pada kategori sedang yaitu sebanyak 8 responden $(13,3 \%)$.

3. Pengaruh pendidikan kesehatan dengan video edukasi tentang bullying terhadap perilaku bullying pada anak di SD Negeri Pujokusuman 1 Yogyakarta. Hasil analisa menggunakan uji Wilcoxon Signed Rank Test menunjukkan adanya pengaruh pendidikan kesehatan dengan video edukasi tentang bullying terhadap perilaku bullying pada anak di SD Negeri Puokusuman 1 Yogyakarta dan terdapat perbedaan yang signifikan antara sebelum dan sesudah diberikan pendidikan kesehatan. Hal ini dikarenakan nilai $p=0,000<a=0,05$ dengan artian Ha diterima.

\section{Ucapan Terima Kasih}

Dalam hal ini penulis mengucapkan terima kasih kepada STIKES Surya Global Yogyakarta yang telah memberikan dukungan moril maupun materiil dalam penyelesaian publikasi ini.

\section{Daftar Pustaka}

Aeni, N., \& Yuhandini, D. S. (2018). Pengaruh Pendidikan Kesehatan Dengan Media Video Dan Metode Demonstrasi 
Terhadap Pengetahuan SADARI. Jurnal

Care Vol .6, No.2 , 164 -169

Araya, W., Natalia, D., \& Marida, C. (2018). Pengaruh Pendidikan Kesehatan Tentang Bullying Dengan Metode Role Play Terhadap Pengatahuan Dan Sikap Remaja SMPN. Dinamika Kesehatan, Vol 9 No. 2 Desember 2018, 612.

Aulya, A., Ilyas, A., \& Ifdil. (2016). Perbedaan Perilaku Agresif Siswa Laki-laki Dan Siswa Perempuan . Universitas Negeri Padang .

Danu. (2013). Yogyakarta Menduduki Peringkat Tertinggi Kasus Bullying. Retrieved Desember 11, 2018, from Radio edukasi: http://radioedukasi.kemdikbud.go.id/re ad/869/yogyakarta-mendudukiperingkat-tertinggi-kasus-bullying.html

Diyantini, N. K., Yanti, N. L., \& Lismawati, S. M. (2015). Hubungan Karakteristik Dan KEpribadian Anak Dengan Kejadian Bullying Pada Siswa Kelas V Di SD "X" Di Kabupaten Bandung. Program Studi Ilmu Keperawatan Fakultas Kedokteran Universitas Udayana Denpasar ISSN: 2303-1298

Mulachela, Z. H. (2017). perilaku bullying pada remaja ditinjau dari self esteem dan jenis kelamin. Fakultas Psikologi Universitas Muhammadiyah Surakarta .

Notoatmodjo, S. (2012). Promosi Kesehatan dan Perilaku Kesehatan. Jakarta: Rineka Cipta.

Notoatmodjo, S., Hassan, A., Hadi, E. N., \& Krianto, T. (2012). Promosi Kesehatan Di Sekolah. Jakarta: Rineka Cipta.

Nursaid, I., Hartini, S., \& Astuti, R. (2016). Pengaruh Pendidikan Kesehatan Bahaya Merokok Terhadap Perubahan Sikap Anak tentang Merokok Di SDIT Al-Firdaus Gubug. Alumni Program Studi S.1 Ilmu Keperawatan STIKES Telogorejo Semarang, Dosen Program Studi S.1 Ilmu Keperawatan
STIKES Telogorejo Semarang, Dosen Jurusan S.1 Fakultas Kesehatan Masyarakat Unimus Semarang .

PH, L., Yulianto, E., \& Hermanto. (2018). Pengaruh Pendidikan Kesehatan Personal Hygiene Terhadap Tingkat Pengetahuan Dan Sikap Masyarakat. Jurnal Keperawatan Komprehensif Vol. 4 No. 1, Januari 2018:1-6, 1.

Putri, M. (2018). Hubungan Kepercayaan Diri dan Dukungan Teman Sebaya Dengan Jenis Perilaku Bullying di MTsN Lawang Mandahiling Kecamatan Salimpaung Tahun 2017. Vol. XII. No.8, Juli 2018, 109.

Rahmawati, D. L. (2017). Pengaruh Pendidikan Kesehatan Dengan Media Audiovisual terhadap Perilaku Personal Hygiene siswa SD Muhammadiyah Kranggan Teempel Sleman. Fakultas Ilmu Kesehatan Universitas Aisyiah yogyakarta.

Saputri, E., Hartati, E., \& Galuh, M. (2018). Evektivitas Pendidikan Kesehatan Dengan Metode Audiovisual Terhadap Perilaku Tentang Jajanan Sehat Dan Aman PAda Anak Kelas 4 dan \% SDN Srondol Wetan 06 Banyu Manik Semarang. Jurnal Keperawatan Komunitas Program Studi Ilmu Keperawatan STIKES Tegalrejo Semarang .

Sari, O. N., Hartati, E., \& Supriyono, M. (2015). Efektifitas Pendidikan Kesehatan Melalui PeerGroup Tentang PHBS Terhadap Pengetahuan, Sikap dan Perilaku Membuang Sampah Siswa SDN Sendangmulyo 01 Semarang. Alumni Program Studi S1 Ilmu Keperawatan STIKES Telogorejo Semarang, Dosen Jurusan Keperawatan UNDIP Semarang, Epidemiolog Kesehatan Dinas Kesehatan Kota Semarang .

Suryaningseh, W., \& Mamnu'ah. (2016). Pengaruh Pendidikan Kesehatan Melalui Audiovisual Terhadap Perilaku Bullying Pada Anak Usia Sekolah Di SD Muhammadiyah Mlagi Gamping 
Sleman Yogyakarta. Universitas 'Aisyiyah Yogyakarta.

Wiyani, N. A. (2014). Save Our Childrend From School Bullying (II ed.). Yogyakarta: AR_RUZZ MEDIA.

Yasinta, V. (2017). Di Jepang, Kasus "Bullying" di Sekolah Meningkat Tajam. Retrieved Desember 16, 2018, from Kompas.com: https://internasional.kompas.com/read/ 2017/10/27/16050131/di-jepangkasus-bullying-di-sekolah-meningkattajam 